\title{
Quantitative description of oscillatory zoning in basaltic to dacitic plagioclases from the Shirahama Group, Japan
}

\author{
Akira Tsune $^{1}$ and Atsushi Toramaru ${ }^{2}$ \\ ${ }^{1}$ Non-profit Organization Sakurajima Museum, 1078 Furusato, Kagoshima 891-1544, Japan \\ ${ }^{2}$ Department of Earth and Planetary Sciences, Graduate School of Sciences, Kyushu University, \\ 6-10-1 Hakozaki, Fukuoka 812-8581, Japan
}

(Received August 22, 2006; Revised January 8, 2008; Accepted January 9, 2008; Online published July 4, 2008)

\begin{abstract}
New criteria related to the origin of oscillatory zoning (OZ) in plagioclase are presented. We compare the OZs in basaltic to those of dacitic plagioclases in the tholeiitic series volcanic rocks of the Shirahama Group, Izu Peninsula, Japan. Nomarski differential interference contrast (NDIC) images of the etched thin sections are used to measure zone thicknesses of the OZs. The normalized standard deviations per data series of the thicknesses are then calculated. We found that the average thicknesses are almost constant (mostly from 2 to $3 \mu \mathrm{m}$ ) through all the rock samples. This constancy corresponds to our idea that the length of oscillation, $D / V$ ( $D$ : diffusivity in the melt; $V$ : growth velocity of plagioclase) is almost constant for a variety of melt viscosity because strong dependences on the viscosity of $D$ and $V$ are canceled out in $D / V$. Consequently, we concluded that the growth of the $\mathrm{OZ}$ is basically controlled by an interface kinetics mechanism. In contrast, the plagioclases in $\mathrm{SiO}_{2}$-rich rocks have the following features: (1) larger standard deviations, (2) abundant erode-like zones, and (3) large oscillation amplitudes. These features reveal that the $\mathrm{OZ}$ patterns of plagioclases in more silicic magmas are disturbed due to change of the environmental parameters under the magma dynamics.
\end{abstract}

Key words: Plagioclase, oscillatory zoning, zoning pattern, zone thickness.

\section{Introduction}

The oscillatory zoning (OZ) found in magmatic plagioclases has been of scientific interest. Many researchers have attempted to explain the OZs in relation to the periodic changes in the physical and chemical conditions in magma chambers (e.g., Wiebe, 1968; Anderson, 1984; Stamatelopoulou-Seymour et al., 1990; Singer et al., 1993, 1995; Hattori and Sato, 1996; Shore and Fowler, 1996; Stewart and Fowler, 2001) as well as to a product of selforganization process (e.g., Haase et al., 1980; Allègre et al., 1981; Lasaga, 1982; L'Heureux and Fowler, 1996).

The OZ in plagioclase has been investigated by various techniques, including microprobe analysis, laser interferometry, Nomarski differential interference contrast (NDIC) microscopy, back-scattered electron (BSE) images, and mathematical data processing (e.g., Pearce and Kolisnik, 1990; Singer et al., 1993; Stewart and Fowler, 2001). The most recent approach, which uses two-dimensional grayscale data of BSE images with the electron microprobe calibration (Ginibre et al., 2002), has contributed to our knowledge of the chemical and morphological characteristics of the zones and a more detailed understanding of the magmatic system (e.g., Wallace and Bergantz, 2002, 2005; Perugini et al., 2005). This approach has been used to perform chaotic analysis, such as the G-P method (Grossberger and Procaccia, 1983) which requires many data points or de-

Copyright (c) The Society of Geomagnetism and Earth, Planetary and Space Sciences (SGEPSS); The Seismological Society of Japan; The Volcanological Society of Japan; The Geodetic Society of Japan; The Japanese Society for Planetary Sciences; TERRAPUB tailed profiles of chemical traverses of $\mathrm{OZ}$ (e.g., Holten et al., 1997; Perugini et al., 2005).

The zoning patterns have been classified by Pearce and Kolisnik (1990) and Ginibre et al. (2002), and mechanisms of origin have also been proposed based on these classifications. Pearce and Kolisnik (1990) have classified OZs into two types: type 1 (small-scale OZs), smaller zones $(<10 \mu \mathrm{m})$ with compositional amplitudes $<5$ An\%; type 2 (large-scale OZs), larger zones $(10-50 \mu \mathrm{m})$ with large amplitudes (5-30 An\%) and clearly eroded tracks. Since the dissolution features are commonly observed in both type 1 and 2, Pearce and Kolisnik consider that various-scale dynamics of magma are involved in the mechanisms of the formations of type 1 and 2 zones; type 1 is formed through small-scale convection in a diffusion-controlled chemical layer, whereas type 2 is formed in large-scale convective magma. In contrast, Ginibre et al . (2002) report the existence of small-scale OZs with low amplitudes, small thicknesses, and no-truncated shapes in nature-in addition to the types 1 and 2 of Pearce and Kolisnik (1990). Ginibre et al. (2002) report that the newly found zones may be formed by a mechanism of interface kinetics.

However, there are a number of problems in the treatment of the small-scale OZ, and these problems prevent a clear understanding the origin of the small-scale OZ. One problem is that there is a lack of well-designed approaches for determining whether a kinetic mechanism is predominantly involved in the small-scale OZ growth (Shore and Fowler, 1996). The second problem is that there is still a limit to the measurement of the OZ. The magnitudes of the spa- 
tial and chemical resolutions determined using the method of Ginibre et al. (2002) are $0.5 \mu \mathrm{m}$ and $0.5 \mathrm{~mol} \%$, respectively. However, these are still insufficient for obtaining detailed profiles of oscillation profiles with the wavelengths of small-scale OZ (1-2 $\mu \mathrm{m})$. Moreover, although a knowledge of whether the chemical profiles are symmetrical or asymmetrical shapes is of interest for acquiring an understanding of the origin of OZ (Sibley et al., 1976; Pearce and Kolisnik, 1990; Tsune and Toramaru, 2007), the shape of the small-scale OZ is still a matter of debate. Consequently, an alternative approach for measuring the compositional profiles is required in order to gain an understanding of the origin of the $\mathrm{OZ}$, and this will require new criteria proving that the small-scale OZ patterns are controlled by kinetic mechanisms.

To overcome this unsatisfactory situation, it is important to examine the relation between the physical properties of the magmas and the characteristics of the OZ. This relation is important because the OZ is the result of crystal growth processes and magma dynamics, and these processes should be dependent on the physical properties of the environment. A new insight into the dominant process that controls $\mathrm{OZ}$ growth may be provided from the relation between the properties and the characteristics of OZ, through a consideration of the processes and the controlling parameters.

However, since the physical properties are strongly dependent on the chemical compositions of magma, an effective approach would be to examine the characteristics of the OZs among basaltic, andesitic, and dacitic rocks. Such studies have been performed by Stamatelopoulou-Seymour et al. (1990), Singer et al. (1993) and Tsune and Toramaru (2004), among others. These studies have shown that plagioclases in the $\mathrm{SiO}_{2}$-rich magmas have abundant truncated zones and the large amplitudes. Singer et al. (1993) discuss a variety of magmatic dynamics based on Stokes velocities and retention times estimated from the physical properties. However, the quantitative comparisons among various $\mathrm{OZ}$ patterns for a variety of volcanic rocks have been carried out well. Moreover, the small-scale OZ was not described and discussed in these earlier studies.

In order to obtain representative data of the rock samples, we used the thicknesses of zones in the OZ because information on the $\mathrm{OZ}$ formed by the magma convection or by a growth kinetic mechanism is included in the thicknesses. With respect to the convective origin, since the thickness corresponds to growth length formed during a periodic movement of magma, the magnitude of the thickness may reflect time scales related to convection. As to the origin of growth kinetics, the magnitude of the thickness should be related to variables of crystal growth, such as growth velocity and thickness of the diffusion layer (e.g., Wang and Merino, 1993; L'Heureux and Fowler, 1996; Tsune and Toramaru, 2007).

Here, we compare the statistical characteristics of the zone thicknesses of plagioclases among the wide variety of bulk compositions from basalt to dacite. The zone thicknesses were measured on NDIC images (similar to Higman and Pearce, 1993). The data are used to construct a data series of zone thicknesses, and averages of the thicknesses and standard deviations (SD) of the data series are then ex- amined as statistical quantities.

When investigating the small-scale OZ, we would like to avoid the signature of crust assimilation or mixing with a different magma. The sampled plagioclases are from the Shirahama Group tholeiitic rocks (Tamura, 1995), which are formed by closed system crystal fractionation (Tamura, 1994, 1995). Therefore, it is most likely that the OZs in sampled plagioclases are not affected by strong crust assimilation or mixing with a different magma in an open system.

\section{Sample}

The analyzed samples of volcanic rocks are from the Shirahama Group, Miocene to Pliocene, the Izu Peninsula, southwest of Tokyo, Japan (Kano, 1989; Tamura, 1994). The Shirahama Group consists of shallow submarine sedimentary rocks (pyroclastic rocks, lava flows, and intrusive rocks, among others; Kano, 1989). The compositions of the volcanic rocks of the Shirahama Group range from basalt to rhyolite (48-75 $\mathrm{SiO}_{2}$ wt.\%; Tamura, 1994), and the chemical variation can be divided into two rock series-tholeiitic and calc-alkaline series (Tamura, 1994, 1995). We selected rocks that belong to the tholeiitic series, as these can be successfully explained by a sequential crystal fractionation (olivine, plagioclase, pyroxene and Fe-Ti oxide) from basalt to dacite (Tamura, 1994). This explanation is supported by major element mass balance models and trace element variation in addition to the glass compositions and the isotropic data of Sr and Nd (Tamura and Nakamura, 1996). The selection of the samples enables us to avoid the treatment of the OZs that are formed due to mixing with country rocks and/or magmas of different origins.

The examined nine rock samples (one basalt, four andesite, and four dacite samples) have no quartz and hornblende as phenocrysts, even in the dacite (Tamura, 1994). The texture of the basalt is porphyritic with intergranular groundmass and abundant phenocrysts (>30 vol.\%), whereas those of the andesites and the dacites are relatively poor in phenocrysts $(<10 \mathrm{vol} . \%)$. The phenocrysts are plagioclase, augite, and $\mathrm{Fe}-\mathrm{Ti}$ oxide in the basalt, and plagioclases, Fe-Ti oxides, augite, and orthopyroxene in the andesites and the dacites. Crystal aggregates (plagioclase \pm pyroxene $\pm \mathrm{Fe}$-Ti oxide) are frequently observed in the andesites and the dacites. Apatite microphenocrysts with $0.3-$ 0.5 vol. $\%$ are formed in the dacites only. The phenocrysts are $0.4-4.0 \mathrm{~mm}$ long in the basalt, $0.2-2.0 \mathrm{~mm}$ in the andesites, and $0.1-0.5 \mathrm{~mm}$ in the dacites (Tsune and Toramaru, 2004).

The major elements and modal compositions (Tsune and Toramaru, 2004) in addition to the physical properties, including viscosities of the samples, are summarized in Table 1 . The major element compositions were determined by X-ray fluorescence analysis with a Rigaku 3270 spectrometer at the Department of Science, Kanazawa University. The operating conditions were $50 \mathrm{kV}$ accelerating voltage and $20 \mathrm{~mA}$ current. Modal compositions were determined by the point-counting method, with 2000-4000 points counted per thin section. The mineral compositions were determined using a JEOL JXA-8800R electron microprobe at Kanazawa University. The operating conditions were $15 \mathrm{kV}$ 
Table 1. Whole rock major elements, modal compositions, and rheological parameters of volcanic rocks in the Shirahama Group.

\begin{tabular}{|c|c|c|c|c|c|c|c|c|c|}
\hline \multirow[b]{2}{*}{ sample name } & \multirow{2}{*}{$\begin{array}{c}\text { basalt } \\
314\end{array}$} & \multicolumn{4}{|c|}{ andesite } & \multicolumn{4}{|l|}{ dacite } \\
\hline & & 326 & $305 \mathrm{~A}$ & $305 B$ & $312-3$ & 300 & $311-3$ & $312-1$ & 301 \\
\hline \multicolumn{10}{|c|}{ Major-elements compositions (wt.\%) } \\
\hline $\mathrm{SiO}_{2}$ & 48.86 & 56.52 & 59.23 & 59.68 & 61.21 & 63.09 & 63.54 & 64.35 & 64.90 \\
\hline $\mathrm{TiO}_{2}$ & 1.02 & 1.15 & 0.79 & 0.88 & 0.80 & 0.88 & 0.84 & 0.91 & 0.77 \\
\hline $\mathrm{Al}_{2} \mathrm{O}_{3}$ & 20.30 & 18.21 & 16.99 & 15.98 & 17.55 & 15.74 & 15.87 & 15.74 & 16.07 \\
\hline $\mathrm{FeO}^{*}$ & 9.19 & 8.09 & 7.01 & 7.54 & 5.47 & 5.45 & 5.77 & 5.39 & 4.15 \\
\hline $\mathrm{MnO}$ & 0.16 & 0.12 & 0.24 & 0.21 & 0.13 & 0.10 & 0.17 & 0.14 & 0.07 \\
\hline $\mathrm{MgO}$ & 3.25 & 2.59 & 2.13 & 2.40 & 1.47 & 1.77 & 1.58 & 1.37 & 0.95 \\
\hline $\mathrm{CaO}$ & 11.49 & 7.95 & 6.65 & 6.09 & 6.29 & 4.25 & 4.77 & 4.58 & 3.96 \\
\hline $\mathrm{Na}_{2} \mathrm{O}$ & 2.49 & 3.45 & 3.92 & 3.91 & 4.03 & 4.62 & 4.65 & 4.67 & 4.80 \\
\hline $\mathrm{K}_{2} \mathrm{O}$ & 0.31 & 0.81 & 0.94 & 1.32 & 1.39 & 1.20 & 1.10 & 1.24 & 1.34 \\
\hline $\mathrm{P}_{2} \mathrm{O}_{5}$ & 0.14 & 0.17 & 0.30 & 0.25 & 0.23 & 0.30 & 0.29 & 0.33 & 0.23 \\
\hline Total & 97.21 & 99.06 & 98.20 & 98.26 & 98.57 & 97.40 & 98.58 & 98.72 & 97.24 \\
\hline \multicolumn{10}{|c|}{ Modal compositions ( $\mathrm{vol} . \%$ ) of phenocrysts (>0.1mm) } \\
\hline \multicolumn{10}{|l|}{ Phenocrysts } \\
\hline Plagioclase & 33.1 & 11.2 & 13.6 & 12.4 & 19.3 & 10.8 & 5.8 & 7.6 & 3.9 \\
\hline Clinopyroxene & 0.1 & 0.6 & 1.1 & 2.6 & 1.3 & 0.5 & 0.1 & 2.1 & 0.1 \\
\hline Orthopyroxene & - & Trace & 0.4 & 0.3 & 0.1 & 0.1 & Trace & Trace & Trace \\
\hline Fe-Ti Oxides & 0.5 & 0.2 & 0.8 & 1.3 & 0.8 & 0.7 & 0.4 & 1.3 & 0.4 \\
\hline Apatite & - & - & - & - & - & - & Trace & - & Trace \\
\hline Groundmass & 66.3 & 88.0 & 84.1 & 83.4 & 78.5 & 87.9 & 93.7 & 88.9 & 95.6 \\
\hline \multicolumn{10}{|l|}{ physical properties* } \\
\hline temperature $\left[{ }^{\circ} \mathrm{C}\right]$ & 1140 & 1079 & 1061 & 1064 & 1022 & 1023 & 947 & 975 & 920 \\
\hline liquid $\rho\left[\mathrm{g} / \mathrm{cm}^{3}\right]$ & 2.63 & 2.47 & 2.43 & 2.42 & 2.39 & 2.25 & 2.26 & 2.25 & 2.26 \\
\hline liquid $\eta\left[\log _{10}\right.$ poise $]$ & 2.76 & 3.66 & 4.13 & 4.09 & 4.86 & 3.33 & 3.84 & 3.84 & 4.4 \\
\hline
\end{tabular}

Note: Compositional data are obtained by XRF. $\mathrm{FeO}^{\star}$ is total $\mathrm{Fe}$ as $\mathrm{FeO}$. Modal compositions are obtained by point counting method. All rocks are free from hornblende and quartz. Data of major elements and modal compositions are from Tsune and Toramaru (2004).

*Physical properties are defined in the text.

Table 2. Plagioclases and the data series of the $\mathrm{OZ}$ in the rock samples.

\begin{tabular}{|c|c|c|c|c|c|c|c|c|c|}
\hline \multirow[b]{2}{*}{ sample name } & \multirow{2}{*}{$\frac{\text { basalt }}{314}$} & \multicolumn{4}{|c|}{ andesite } & \multicolumn{4}{|l|}{ dacite } \\
\hline & & 326 & $305 A$ & $305 B$ & $312-3$ & 300 & $311-3$ & $312-1$ & 301 \\
\hline $\mathrm{SiO}_{2}$ composition (wt.\%) & 48.86 & 56.52 & 59.23 & 59.68 & 61.21 & 63.09 & 63.54 & 64.35 & 64.90 \\
\hline \multicolumn{10}{|c|}{ plagioclases $(>0.1 \mathrm{~mm})$ in the samples } \\
\hline average size $(\mathrm{mm})$ & 0.62 & 0.40 & 0.35 & 0.20 & 0.77 & 0.24 & 0.41 & 0.28 & 0.22 \\
\hline maximum size $(\mathrm{mm})$ & 3.0 & 1.8 & 1.3 & 0.70 & 3.1 & 1.3 & 3.3 & 1.2 & 0.94 \\
\hline An of phenocryst cores (mol.\%) & $98-92$ & $97-70$ & $88-66$ & $83-69$ & $87-70$ & $68-56$ & $86-45$ & $75-61$ & $65-55$ \\
\hline An in outer regions (mol.\%) & $97-84$ & $92-79$ & $87-61$ & $81-70$ & $86-74$ & $67-59$ & $67-62$ & $68-50$ & $71-57$ \\
\hline \multicolumn{10}{|c|}{ significantly rough zones (dissolution surfaces) in plagioclases } \\
\hline maximum numbers counted in a plagioclase & 2 & 3 & 5 & 4 & 5 & 13 & 23 & 14 & 30 \\
\hline \multicolumn{10}{|l|}{ selected plagioclases } \\
\hline numbers of plagioclases selected & 46 & 56 & 48 & 39 & 37 & 44 & 43 & 59 & 63 \\
\hline numbers of data series selected & 96 & 86 & 101 & 80 & 71 & 90 & 88 & 111 & 127 \\
\hline total of zone thicknesses measured & 2200 & 1675 & 3216 & 2445 & 2030 & 2651 & 1901 & 2006 & 4752 \\
\hline numbers of zones per a data series & $9-54$ & $8-45$ & $10-98$ & $11-81$ & $9-85$ & 9-105 & $10-83$ & $11-56$ & $11-119$ \\
\hline
\end{tabular}

Note: Crystal size was by image processing, calculated from square root of the area. An contents are by electron microprobe.

Size data are from Tsune and Toramaru (2004). Significantly rough zones are with resorbed tracks at the crystal corners and edge lines.

accelerating potential for plagioclase, $20 \mathrm{kV}$ for pyroxenes and Fe-Ti oxides, $20 \mathrm{nA}$ electron beam current, $3 \mu \mathrm{m}$ beam diameter, and counting times of $30 \mathrm{~s}$.

We estimated the densities and viscosities for the basalt to dacites as follows. Since most of included crystals are plagioclases (Table 1), the chemical compositions of the melts or groundmasses are obtained by a mass balance calculation between the bulk and the plagioclases. MELTS com- putation (Ghiorso and Sack, 1995) is performed under conditions of 2 kbar and FMQ buffer in order to determine the liquid temperatures of the estimated melt compositions. We assume $1 \% \mathrm{H}_{2} \mathrm{O}$ in basalt, $2 \% \mathrm{H}_{2} \mathrm{O}$ in andesite, and $5 \%$ $\mathrm{H}_{2} \mathrm{O}$ in dacite (Tamura, 1994). The 1-atm magma densities are calculated based on the partial molar volume data of Lange (1994) and Ochs and Lange (1999). Melt viscosities are calculated following Shaw (1972), and range from 


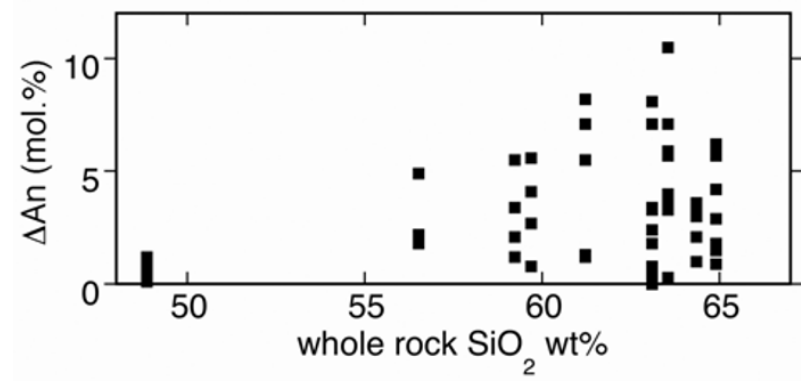

Fig. 1. Amplitudes of chemical oscillation in plagioclases are plotted against the whole rock $\mathrm{SiO}_{2}$ compositions. A solid square indicates the maximum differences among some measured compositions for each oscillatory region. The differences are regarded as the apparent amplitudes of the OZs.

\section{$10^{2.8}$ to $10^{4.9}$ poise (Table 1$)$}

The anorthite contents of cores of plagioclase phenocrysts range from $\mathrm{An}_{98}$ to $\mathrm{An}_{92}$ in the basalt, $\mathrm{An}_{97}$ to $\mathrm{An}_{66}$ in the andesites, and $\mathrm{An}_{70}$ to $\mathrm{An}_{60}$ in the dacites (Table 2). The compositions of the outer regions range from $\mathrm{An}_{97}$ to $\mathrm{An}_{84}$ in the basalt, $A n_{92}$ to $A n_{61}$ in the andesites, and $A n_{70}$ to $\mathrm{An}_{51}$ in the dacites (Table 2). The compositions of plagioclases surrounding the melt inclusions in dacitic rocks are bimodal around $\mathrm{An}_{85}$ and $\mathrm{An}_{45}$. Compositional fluctuations in the $\mathrm{OZ}$ regions of plagioclase against the whole rock $\mathrm{SiO}_{2}$ contents are shown in Fig. 1. The maximum differences among some measured points in the $\mathrm{OZ}$ region are plotted, and the differences are regarded as apparent amplitudes. The amplitudes in the basalt are about 1-2 mol\% An, whereas those in most of andesitic to dacitic are up to $10 \mathrm{~mol} \%$.

We also describe the characteristics of the observed OZs. There are 10-100 zones per plagioclase phenocryst. The thickness of the zones mostly ranges from 1 to $5 \mu \mathrm{m}$. Zones are commonly no-curvy and flat; rough or truncated zones show the discordant signature, indicating the erosion or resorption events, which have shapes of irregularly embayed crystal corners and crystal faces (Pearce and Kolisnik, 1990). The rough zones, which correspond to the type 2 zones of Pearce and Kolisnik (1990) and to dissolution surfaces of Stamatelopoulou-Seymour et al. (1990), are frequently observed in dacitic plagioclases, whereas most of the zones in the basaltic plagioclases are smooth and have no eroded tracks. The number of rough zones observed in a plagioclase phenocryst increases systematically with whole rock $\mathrm{SiO}_{2}$ compositions (Tsune and Toramaru, 2004; Table 2).

\section{Methods}

\subsection{Observations with NDIC microscopy}

An NDIC microscope was used to observe the OZ of plagioclase and to measure zone thicknesses. NDIC microscopy can reveal features of the OZ on a fine scale $(<1 \mu \mathrm{m})$ in the etched surface (Anderson, 1983; Pearce et al., 1987). Polished thin sections were etched by fluoboric acid $\left(\mathrm{HBF}_{4}\right.$; Anderson, 1983), in order to make reliefs that show the conditions of the anorthite contents (the An-rich parts erode more). The reliefs on the polished surfaces can be visualized as an interference color image by the NDIC
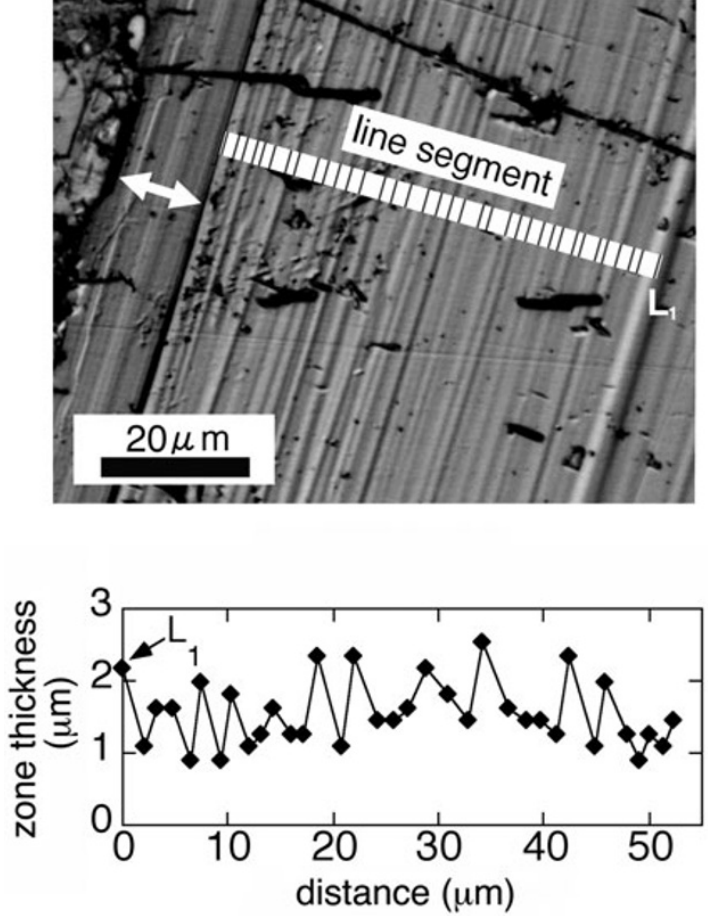

Fig. 2. Data series of zone thickness of plagioclase (1 mm long crystal) in the basaltic sample (314). The upper photo shows the enlarged parts of the oscillatory region. We measured zone thicknesses along a line segment from the core to rim. The line segment is perpendicular to the crystal face. The double-headed arrow shows the most outer rim of the crystal. The lower figure shows the zone thickness plotted against the distance. A set of the zone thicknesses is examined as a data series.

prism.

\subsection{Quantitative description of the $\mathrm{OZ}$ pattern}

Image processing, measurements of zone thicknesses, and data series of the $\mathrm{OZ}$

Images of the etched surfaces of plagioclases using reflected-light NDIC microscopy were saved in PC through a Nicon HC-300Zi digital camera. The resolution of the images is $0.18 \mu \mathrm{m}$, which corresponds to a single pixel size, and the size of an image is $1280 \times 1024$ pixels. The zone thicknesses of the OZ were measured using image processing software, Adobe Photoshop ${ }^{\mathrm{TM}}$. Each zone thickness was sequentially measured along the direction perpendicular to interfaces between the neighbor zones (Fig. 2). Each zone thickness was denoted as $L_{i}(n)$, where the subscript $i$ is the identification number of the crystal and zone number, $n$ is the order of the zone counted outward from the inner parts of $\mathrm{OZ}$ regions of the phenocrysts. We therefore obtained the following data series of zone thicknesses of plagioclase grain $i$ in a given thin section:

$$
\left\{L_{i}\right\}=\left\{L_{i}(1), L_{i}(2) \ldots, L_{i}\left(n_{i}\right)\right\}
$$

\subsection{Statistical treatment for data series of zone thick- nesses}

We statistically treated the data series in order to compare the characteristics of the OZ among different plagioclase crystals. First, the average thicknesses of each data series, $\overline{L_{i}}$, were calculated. The ranges of the averages were then examined among the rock samples. Second, the data of each series were normalized using $\overline{L_{i}}$ to obtain the normalized 
data series $\left\{L_{i}^{*}\right\}$ :

$$
\begin{aligned}
\left\{L_{i}^{*}\right\} & =\left\{\frac{L_{i}(1)}{\overline{L_{i}}}, \frac{L_{i}(2)}{\overline{L_{i}}}, \ldots, \frac{L_{i}\left(n_{i}\right)}{\overline{L_{i}}}\right\} \\
& =\left\{L_{i}^{*}(1), L_{i}^{*}(2), \ldots, L_{i}^{*}\left(n_{i}\right)\right\}
\end{aligned}
$$

where

$$
\overline{L_{i}}=\sum_{k=1}^{n} \frac{L_{i}(k)}{n_{i}}
$$

Standard deviations (SD) of the normalized data series, as an indicator of the spatial regularity of the oscillatory structure, were calculated. A small SD value indicates a spatially monotonic OZ pattern, suggesting that all of the zones in the data series have similar thicknesses. A large SD value means a spatially less monotonic $\mathrm{OZ}$ pattern. The ranges of the calculated SD values are displayed for the rock samples.

\subsection{Selected plagioclase phenocrysts}

We select the spatial series of the zones as follows. Since we consider that it is difficult to assess the involvement of a kinetic mechanism from the morphological features of the small-scale OZs, we do not take the morphological or visible features significantly into account in measuring the zone thicknesses. For example, smooth and rough zones (that is, zones with and without resorbed tracks) are not distinguished. In addition, since zone thicknesses are measured independently of the chemical data, we do not used the classification of type 1 and type 2 described in Pearce and Kolisnik (1990).

The series without wavy, crosscut, and significantly embayed shapes of the interfaces are preferentially selected because of the accuracy of the measurement (Pearce and Kolisnik, 1990). This is particularly valid in the dacitic rocks, where only $15-25$ zones within more than 50 zones are countable because of the abundance of significantly rough zones. On the other hand, we do count zones with weakly eroded tracks, which are often eroded only at the crystal corners.

We carefully selected plagioclases which have more than about ten sequential zones because of accurate calculations of the SD value and the average thickness. We chose 40-60 grains among 100-1000 plagioclases for each thin section (about $8 \mathrm{~cm}^{2}$ ) of each rock for the measurements of zone thicknesses. We selected one or two data series from different crystal faces for a crystal. Indices of selected crystal faces are random. There was a total of 70-120 measured data series for each thin section, more than 800 data series, and $>20,000$ measured zones. The outermost rims (typically $10-20 \mu \mathrm{m}$ ) of the phenocrysts were not measured (double-headed arrow in Fig. 2) because the outermost rims are probably overgrown due to the solidification process during magma ascent and emplacement (Anderson, 1984).

\section{Result: Quantitative Characterization of the OZ Patterns}

Figure 3 shows ranges of average thicknesses plotted against whole rock $\mathrm{SiO}_{2}$ contents of the samples. Most of the average thicknesses range from 2 to $3 \mu \mathrm{m}$, although zones thickness of $<1 \mu \mathrm{m}$ or $>10 \mu \mathrm{m}$ are occasionally observed. There is no correlation between the thicknesses and the $\mathrm{SiO}_{2}$ contents.

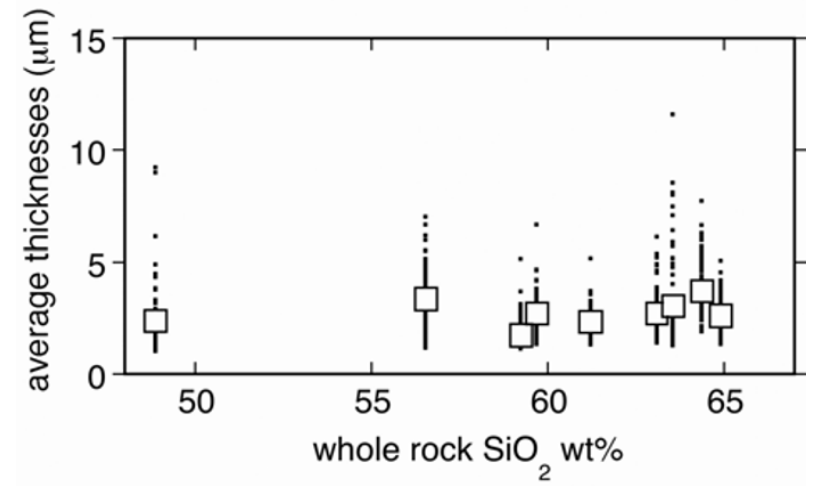

Fig. 3. Averages of measured zone thicknesses of plagioclase OZs against the whole rock $\mathrm{SiO}_{2}$ contents. A dot indicates the average thickness per data series. The open square is the value representative of the rock samples (average).
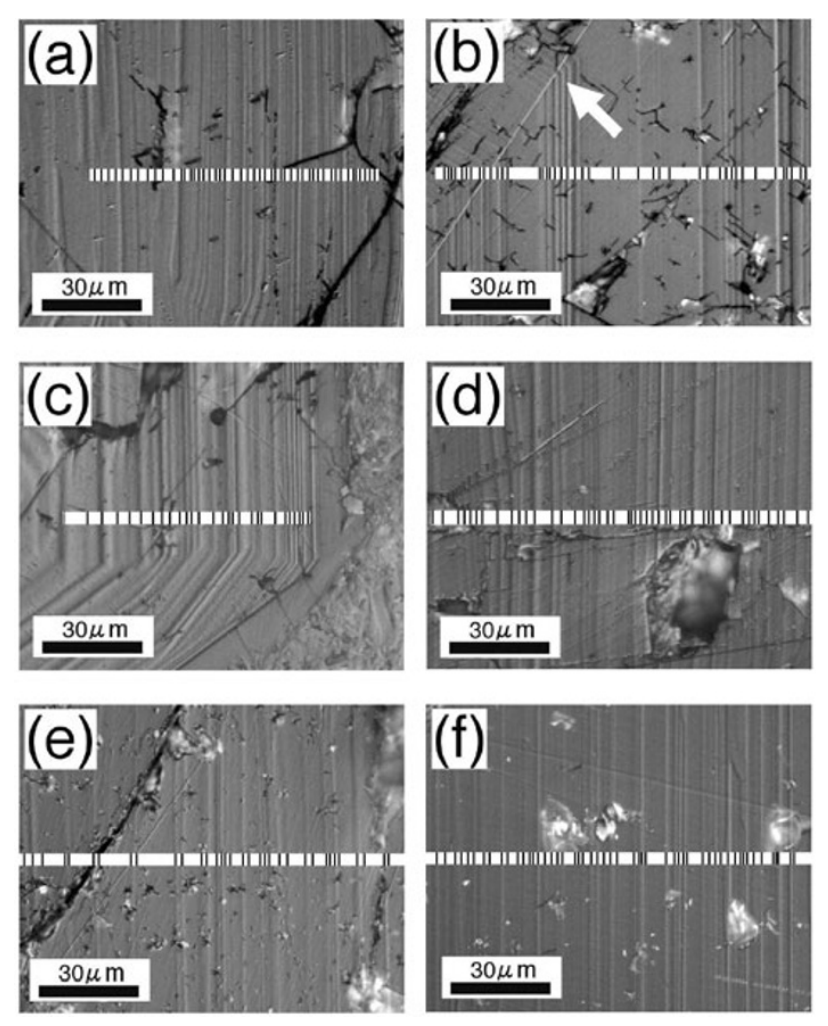

Fig. 4. Representative OZ patterns in the rock samples. (a) Spatially monotonic pattern observed in the basaltic sample 314 (data series name: $15 \mathrm{~b} ; \mathrm{SD}=0.30$ ). (b) Spatially periodic pattern observed in the andesitic sample $305 B$ (data series name: $14 \mathrm{~b} ; \mathrm{SD}=0.82$ ). Note that the crystal corners do not erode (arrow). (c) Spatially damped pattern observed in the andesitic sample 312-3 (data series name: 23a; $\mathrm{SD}=0.52$ ). (d) The rather spatially irregular pattern observed in the andesitic sample 312-3 (data series name: 31a; $\mathrm{SD}=0.46$ ). (e) Spatially periodic pattern observed in the dacitic sample 300 (data series name: $18 \mathrm{a} ; \mathrm{SD}=0.77$ ). (f) Spatially irregular pattern observed in the dacitic sample 301 (data series name: 52c; S.D. $=0.55$ ).

The following $\mathrm{OZ}$ patterns were typically observed in the basaltic (Fig. 4(a)), andesitic (Figs. 4(b), 4(c), 4(d)), and dacitic (Figs. 4(e), 4(f)) plagioclases. (1) Spatially monotonic patterns (Fig. 4(a)) in which each zone has almost the same thicknesses, were frequently observed. (2) Spatially damped patterns (Fig. 4(c)) in which the thicknesses 


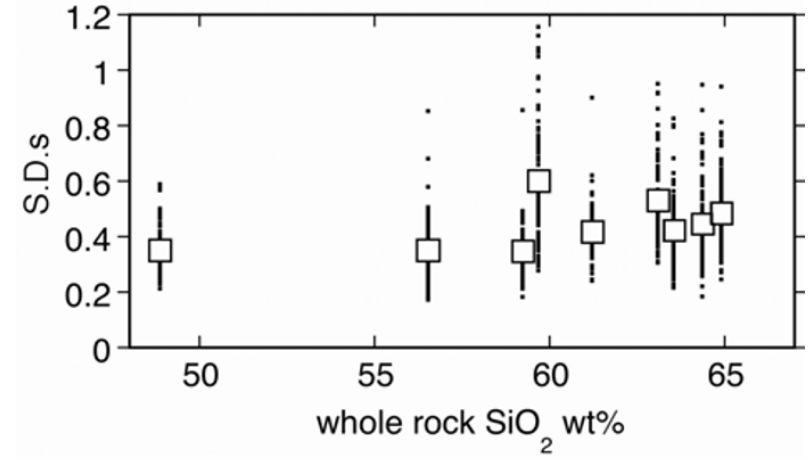

Fig. 5. SD values of normalized data series are plotted against the whole rock $\mathrm{SiO}_{2}$ contents. The dot indications the $\mathrm{SD}$ of data series of a line segment (Fig. 2). The open square indicates the average values for the rock samples.
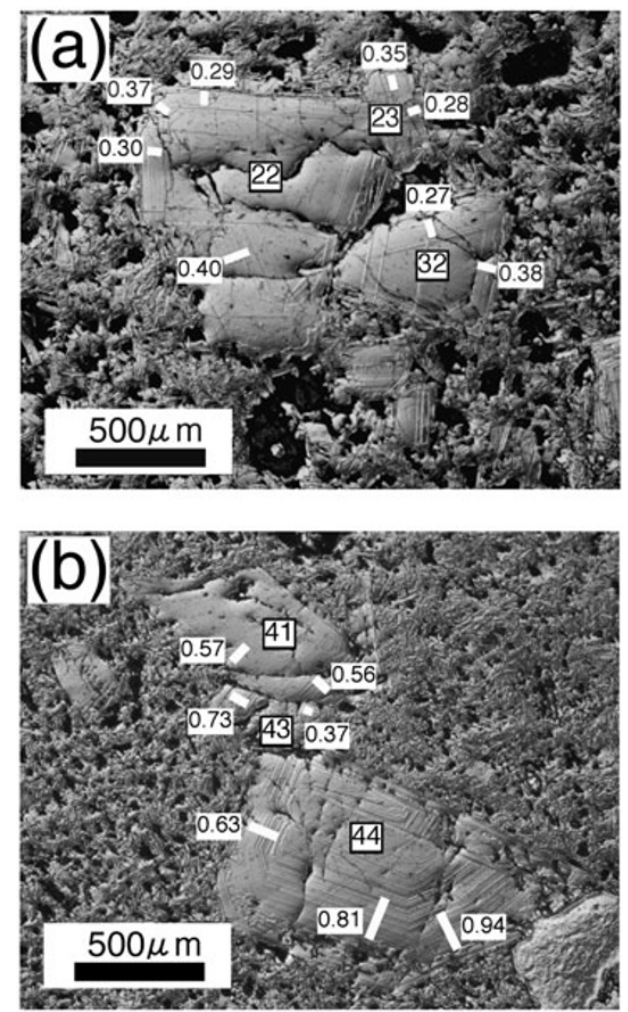

Fig. 6. Representative SD values of the data series of plagioclase OZ in the rock samples. (a) basalt (314) and (b) dacite (301). The numbers of the centers of plagioclases are the identification numbers. The white line segments in the plagioclases are locations at which zone thicknesses are measured. The numbers near the segments are the SD values of the data series.

of zones decrease toward the outer rims were also recognized in all samples, but not many. (3) Spatially modulated or periodic patterns (Figs. 4(b), 4(e)) are repetitions of units consisting of some thin and thick zones. A periodic pattern can be seen when the zone thicknesses are plotted against the zone number counted from the inner zones. Such patterns were only observed among andesitic and dacitic plagioclases. One of the spatially periodic patterns consisted of repetitive units consisting of two zones with extreme thick and thin thicknesses, respectively (Fig. 4(e)), while another pattern consisted of a thick zone followed by sev- eral (1-5) thin zones (Fig. 4(b)). (4) Spatially irregular (random) patterns (Figs. 4(d) and 4(f)) in which the thicknesses of the zones change irregularly with the zone numbers (i.e., toward outer rim) were frequently observed in the andesites and the dacites. In general, the zones of the irregular and modulated patterns are rough or truncated. However, smooth zones in these patterns are also rarely observed (arrow in Fig. 4(b)).

In general, the OZ patterns of plagioclases in the basaltic sample are spatially monotonic, whereas these in the andesites and the dacites are modulated. These qualitative features were supported by the relation between the SD values of the data series and the whole rock compositions (Fig. 5). The data series for OZs of basaltic plagioclases mainly have smaller SD values of $0.20-0.60$ (Fig. 6(a)), whereas those of andesitic and dacitic plagioclases have a wider range of SD values-from 0.30 to 0.80 (Fig. 6(b)).

\section{Discussion}

\subsection{Methodology of the measurement}

The OZ observed on the thin sections includes not only desired information but also some ambiguity. For example, the features of the zones are different for individual crystals and individual crystal faces (Anderson, 1984). Since the crystals on the thin sections are generally cut by angles which have no relationship to the crystallographic angles, the cut angles affect the measured thicknesses of zones in the crystals. Although the measured zone thicknesses are not correct but apparent values on two-dimensional planes randomly cut, the data can be statistically regarded as quantities representative of the rock samples. We consider that there are no large differences between the representative averages of the apparent and correct thicknesses because crystals on the thin section are cut near the centers at a highly probability (Cashman, 1990). Thus, we use the range of the average thickness as the representative of plagioclase zoning included in the rock samples. On the other hand, we use the data of the SD because the effect of the oblique cut is canceled due to normalization by the average thicknesses; in addition, the difference in SD values represents the standard deviation in true thickness distribution.

\subsection{Average of the zone thickness}

Regardless of the wide range of $\mathrm{SiO}_{2}$ contents in the rock samples, most of the average thicknesses are 2-3 $\mu \mathrm{m}$ (Fig. 3). This suggests that the magnitude of the zone thickness is nearly unchangeable for different rock samplesthat is, a variety of the physical properties of the magmas.

We can explain the range of the observed zone thicknesses from the relation among the associated parameters. If a growth kinetics is the dominant process, the wavelength of the grown OZ is controlled by the growth velocity $(V)$ and diffusion of the related components in the melt $(D)$ because both the growth and the diffusion play important roles in the growth mechanism. Studies of numerical simulations of the oscillatory growth also show that the wavelengths of the calculated oscillations are close to the magnitudes of $D / V$ (e.g., L'Heureux and Fowler, 1996). Thus, in this situation, the wavelength can be expressed as $D / V$.

On the other hand, $D$ and $V$ are strongly dependent on the viscosity of the melt, $\eta$. The relation between $\eta$ and 
$D$, known as the Eyring equation, is $D \sim \eta^{-1}$ (e.g., Baker, 1992). The growth velocity of plagioclase is also in inverse proportion to $\eta$ (e.g., Lasaga, 1982). Since the significant dependence of $D / V$ on the $\eta$ is canceled, the value of $D / V$ is regarded as being approximately constant among basaltic to dacitic magma. Furthermore, since the variation in estimated viscosities is within two orders (Table 1), it is expected that the variation in the zone thickness is not large. These assumptions are consistent with the observational results. Consequently, we conclude that the nearly constant average thickness is important evidence indicating that the small-scale OZs are controlled by a kinetic mechanism.

Holten et al. (1997) does not agree with our hypothesis. These researchers have digitized the compositional data of the OZs (garnet, vesuvianite and plagioclase) using electron microprobe and BSE images and subsequently characterized the OZ patterns based on self-affine fractal geometry. They suggest that fluctuation by changes in the surrounding environment is the most important factor in controlling the pattern. However, the compositional resolution of their examined data is equal to or larger than a zone thickness of the small-scale OZ (1- to $2-\mu \mathrm{m}$ diameter beam is used for the measurement). Thus, since they dealt with the large-scale OZ, our hypothesis is not inconsistent with their hypothesis.

\subsection{Comparison with the existing kinetic model}

In this section we discuss the relevance of the existing models to the small-scale OZs that are controlled by a growth kinetics. As Ginibre et al. (2002) mentioned, the results of the existing models contradict the observational data (e.g., Haase et al., 1980; Wang and Merino, 1993; L'Heureux and Fowler, 1996). The observed zone thickness is clearly less than $10 \mu \mathrm{m}$ (Fig. 3), whereas the estimated model results are larger than $10 \mu \mathrm{m}$.

However, there may be some plausible models at the present time. Simulating the improved model of the Sibley et al. (1976), Tsune and Toramaru (2007) demonstrated that the temperature and the undercooling are controlling the amplitude and wavelength. The model by Tsune and Toramaru (2007) assumes that growth velocity is alternately changed with the surface area on the crystal. Since the resulting oscillation has wavelengths less than $10 \mu \mathrm{m}$, the model is a probable mechanism for OZ based on growth kinetics. However, the validity of the model still remains to be confirmed because it is not clear whether the compositional profiles of the natural OZs have sine-waves or not, or asymmetric saw-tooth patterns or not.

On the other hand, the kinetic model of Allègre et al. (1981) may also be plausible. These researchers propose the concept that the actual velocity does not immediately correspond to the concentration in the melt at the growth front. Using their model, they demonstrate that damped oscillatory growth occurs by the small fluctuation. However, the model is less constrained by the wavelength or the amplitude. We propose that constraints by developed theoretical studies are urgently needed.

\subsection{Origins of the observed zoning patterns}

The OZ patterns are mainly categorized into spatially monotonic, periodic, or irregular, as is clearly shown in Figs. 4 and 6. Plagioclases in $\mathrm{SiO}_{2}$-rich magma have periodic, irregular, or random-like patterns. This is supported by the higher $\mathrm{SD}$ in the $\mathrm{SiO}_{2}$-rich rock samples (Fig. 5). Furthermore, the amplitudes of the OZs are larger (Fig. 1), and resorbed tracks in the $\mathrm{OZ}$ regions are frequently observed (Table 2) in the $\mathrm{SiO}_{2}$-rich rock samples. These observations suggest that developments of magmatic convection or internal mixing in higher $\mathrm{SiO}_{2}$ magmas result in crystal dissolutions and influence the subsequent formations of OZs with the higher SD or random-like patterns. Stamatelopoulou-Seymour et al. (1990) and Singer et al. (1993) also demonstrated that the large amplitudes and abundant truncated zones are observed in rocks with a higher content of $\mathrm{SiO}_{2}$. However, they did not refer to possible origins of patterns of the small-scale OZs.

The OZ patterns affected by environmental noise were investigated by Holten et al. (2000) using numerical simulation. As their calculation show, both the zoning patterns and the zone thickness can be disturbed by the noise. Consequently, we conclude that the small-scale OZ patterns are basically kinetic-controlled but that the patterns are modified by magmatic events. However, any discussion of the reasoning that the plagioclases in the $\mathrm{SiO}_{2}$-rich magmas are highly affected by the magmatic events is beyond the scope of the present paper.

The origin of the spatially damped pattern of data series is discussed by Anderson (1984). Using data of natural plagioclases, he demonstrated that a constant volume among zones in a given plagioclase result in a spatially damped pattern. This means that there are somewhat damped trends in all of the observed OZ patterns. On the other hand, spatially damped patterns (Fig. 4(c)) have large SD because of differences between the thicknesses of the inner and outer zones in a plagioclase. However, with few exceptions, most of the data series we examined do not show a significantly damped pattern (Fig. 4(c)). Therefore, the details of the damped pattern are not treated further in our study.

\subsection{Zoning pattern with multi-periodicity}

The chemical waves of the OZ with multi-periodicity, which are observed as spatially periodic or modulated patterns on NDIC microscopy, were found in the $\mathrm{SiO}_{2}$-rich rock samples. The multi-periodicity in the $\mathrm{OZ}$ is important topic and probably a key to our understanding of magma convection or the growth mechanism. In order to understand the importance of the multi-periodicity, it is necessary to take into account the phenomenon called bifurcation in the field of mathematics: a small and smooth change in the parameter values of a dynamical system causes a sudden qualitative change in dynamical behavior of the system. In plagioclase oscillation, a slight change in an environmental parameter (e.g., temperature and viscosity) may cause a sudden occurrence or change of behaviors, such as nooscillation, oscillation, oscillation with double-period, and chaotic behavior. Such bifurcation has been investigated to gain an understanding of the nonlinearity of the dynamical system or the government rules. Obvious multi-periodicity shown in Fig. 4(e) may be evidence that OZ formation is controlled by a deterministic process (e.g., Higman and Pearce, 1993; L'Heureux and Fowler, 1996). 


\section{Concluding Remarks}

The relation between OZ patterns of plagioclase and the whole rock $\mathrm{SiO}_{2}$ content was examined using the tholeiitic series volcanic rocks of the Shirahama Group, Izu Peninsula, Japan. Averages of apparent zone thicknesses measured on NDIC images have similar values, 2-3 $\mu \mathrm{m}$, independent of bulk compositions (basaltic to dacitic). Normalized standard deviations of the spatial series (SD) vary with the bulk compositions and range from 0.20 to 0.60 in basalt and from 0.30 to 0.80 in andesite and dacite. As previous researchers have shown, plagioclases in the $\mathrm{SiO}_{2}$-rich rocks have abundant resorbed tracks and high amplitudes of chemical compositions. Based on our results, we conclude that the crystal growth of the OZ is basically controlled by an interface kinetics mechanism and that the OZ pattern is disturbed by the change of environmental variables due to magmatic events that have occurred predominantly in the silicic magmas.

Acknowledgments. The authors thank Y. Tamura, JAMSTEC for the geological information, field survey and helpful comments. A part of this work was carried out at Kanazawa University. T. Morishita, Kanazawa University gave us technical support in the chemical analysis. Discussions with T. Ikeda and T. Miyamoto, Kyushu University, were beneficial. Reviewers H. Sato and A. D. Fowler are acknowledged for their critical reading of this manuscript. Tsune thanks Izumi A. Tsune for improving this manuscript.

\section{References}

Allègre, C. J., A. Provost, and C. Jaupart, Oscillatory zoning: a pathological case of crystal growth, Nature, 294, 223-228, 1981.

Anderson, A. T., Jr., Oscillatory zoning of Plagioclase Nomarski interference contrast microscopy of etched polished sections, Am. Mineral., 68 , 125-129, 1983.

Anderson, A. T., Jr., Probable relations between plagioclase zoning and magma dynamics, Fuego, Volcano, Guatemala, Am. Mineral., 69, 660676, 1984.

Baker, Don R., Estimation of diffusion coefficients during interdiffusion of geologic melts: Application of transition state theory, Chem. Geol., 98, 11-21, 1992

Cashman, K. V., Textural constraints on the kinetics of crystallization of igneous rocks, Rev. Mineral., 24, 259-314, 1990.

Ghiorso, M. S. and R. O. Sack, Chemical Mass Transfer in Magmatic Processes IV. A revised and internally consistent thermodynamic model for the interpolation and extrapolation of liquid-solid equilibria in magmatic systems at elevated temperatures and pressures, Contrib. Mineral. Petrol., 119, 197-212, 1995.

Ginibre, C., A. Kronz, and G. Worner, High-resolution quantitative imaging of plagioclase composition using accumulated backscattered electron images: new constraints on oscillatory zoning, Contrib. Mineral. Petrol., 142, 436-448, 2002.

Grossberger, P. and I. Procaccia, Measuring the strangeness of strange attractors, Physica D, 9, 189-208, 1983.

Haase, C. S., J. Chadam, D. Feinn, and P. Ortoleva, Oscillatory zoning in plagioclase Feldspar, Science, 209, 272-274, 1980.

Hattori, K. and H. Sato, Magma evolution recorded in plagioclase zoning in 1991 Pinatubo eruption products, Am. Mineral., 81, 982-994, 1996.

Higman, S. L. and T. H. Pearce, Spatiotemporal dynamics in oscillatory zoned magmatic plagioclase, Geophys. Res. Lett., 20, 1935-1938, 1993.

Holten, T., B. Jamtveit, P. Meakin, M. Cortini, J. Blundy, and H. Austrheim, Statistical characteristics and origin of oscillatory zoning in crystals, Am. Mineral., 82, 596-606, 1997.

Holten, T., B. Jamtveit, and P. Meakin, Noise and oscillatory zoning of minerals, Geochim. Cosmochim. Acta, 64, 1893-1904, 2000.

Kano, K., Interactions between andesitic magma and poorly consolidated sediments: examples in the Neogene Shirahama Group, south Izu,
Japan, J. Volcanol. Geotherm. Res., 37, 59-75, 1989.

Lange, R. A., The effect of $\mathrm{H}_{2} \mathrm{O}, \mathrm{CO}_{2}$ and $\mathrm{F}$ on the density and viscosity of silicate melts, in Mineralogical Society of America, Reviews in Mineralogy: Volatiles in Magmas, edited by M. Carroll and J. R. Holloway, 30, 331-369, 1994.

Lasaga, A. C., Toward a master equation in crystal growth, Am. J. Sci., 282, 1264-1288, 1982.

L'Heureux, I. and A. D. Fowler, Isothermal constitutive undercooling as a model for oscillatory zoning in plagioclase, Can. Mineral., 34, 11371147, 1996.

Ochs III, F. A. and R. A. Lange, The Density of Hydrous Magmatic Liquids, Science, 283, 1314-1317, 1999.

Pearce, T. H. and A. M. Kolisnik, Observations of plagioclase zoning using interference imaging, Earth Sci. Rev., 29, 9-26, 1990.

Pearce, T. H., M. P. Griffin, and A. M. Kolisnik, Magmatic crystal stratigraphy and constraints on magma chamber dynamics: laser interference results on individual phenocrysts, J. Geophys. Res., 92, 13745-13752, 1987.

Perugini, D., G. Poli, and L. Valentini, Strange attractors in plagioclase oscillatory zoning: petrological implications, Contrib. Mineral. Petrol., 149, 482-497, 2005.

Shaw, H. R., Viscosities of magmatic silicate liquids, an empirical method of prediction, Am. J. Sci., 272, 870-893, 1972.

Shore, M. and A. D. Fowler, Oscillatory zoning in minerals: A common phenomenon, Can. Mineral., 34, 1111-1126, 1996.

Sibley, D. F., T. A. Vogel, B. M. Walker, and G. Byerly, The origin of oscillatory zoning in plagioclase: A diffusion and growth controlled model, Am. J. Sci., 276, 275-284, 1976.

Singer, B. S., T. H. Pearce, A. M. Kolisnik, and J. D. Myers, Plagioclase zoning in mid-Pleistocene lavas from the Seguam volcanic center, central Aleutian arc, Alaska, Amer. Mineral., 78, 143-157, 1993.

Singer, B. S., M. A. Dungan, and G. D. Layne, Textures and Sr, Ba, Mg, $\mathrm{Fe}, \mathrm{K}$, and $\mathrm{Ti}$ compositional profiles in volcanic plagioclase: clues to dynamics of calc-alkaline magma chambers, Am. Mineral., 80, 776$798,1995$.

Stamatelopoulou-Seymour, K., D. Vlassopoulos, T. H. Pearce, and C. Rice, The record of magma chamber processes in plagioclase phenocrysts at Thera Volcano, Aegean volcanic arc, Greece, Contrib. Mineral. Petrol., 104, 73-84, 1990.

Stewart, M. L. and A. D. Fowler, The nature and occurrence of discrete zoning in plagioclase from recently erupted andesitic volcanic rocks, Montserrat, J. Volcanol. Geotherm. Res., 106, 243-253, 2001.

Tamura, Y., Genesis of Island Arc Magmas by Mantle-Derived Bimodal Magmatism: Evidence from the Shirahama Group, Japan, J. Petrol., 35, 619-645, 1994

Tamura, Y., Liquid lines of descent of island arc magmas and Genesis of Rhyolites: Evidence from the Shirahama Group, Japan, J. Petrol., 36, 417-434, 1995.

Tamura, Y. and E. Nakamura, The Arc Lavas of the Shirahama Group, Japan: Sr and Nd Isotopic Data Indicate Mantle-Derived Bimodal Magmatism, J. Petrol., 37, 1307-1319, 1996.

Tsune, A. and A. Toramaru, Magmatic differentiation process inferred from plagioclase zoning and its pattern, Bull. Volcanol. Soc. Jpn., 49, 249-266, 2004 (in Japanese with English abstract).

Tsune, A. and A. Toramaru, A simple model of oscillatory zoning in magmatic plagioclase: Development of an isothermal undercooling model, Am. Mineral., 92, 1071-1079, 2007.

Wallace, G. S. and G. W. Bergantz, Wavelet-based correlation (WBC) of crystal populations and magma mixing, Earth Planet. Sci. Lett., 202, 133-145, 2002.

Wallace, G. S. and G. W. Bergantz, Reconciling heterogeneity in crystal zoning data: An application of shared characteristic diagrams at Chaos Crags, Lassen Volcanic Center, California, Contrib. Mineral. Petrol., 149, 98-112, 2005.

Wang, Y. and E. Merino, Oscillatory magma crystallization by feedback between the concentrations of the reactant species and mineral growth rates, J. Petrol., 34, 369-382, 1993.

Wiebe, R. A., Plagioclase stratigraphy: a record of magmatic conditions and events in a granitic stock, Am. J. Sci., 266, 690-703, 1968.

A. Tsune (e-mail: atsune@yahoo.co.jp) and A. Toramaru 